Preprints of the

Max Planck Institute for

Research on Collective Goods

Bonn 2008/10

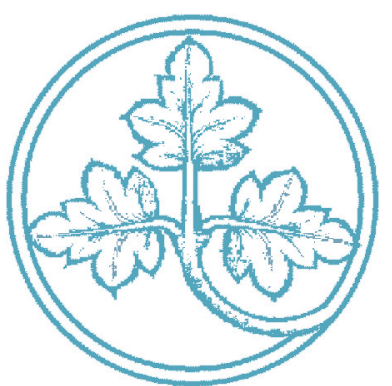

Umbrella Branding and External Certification

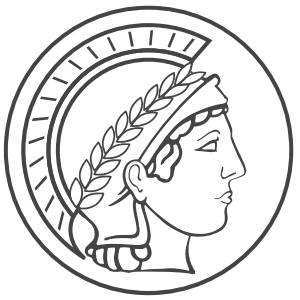




\title{
Umbrella Branding and External Certification
}

\author{
Hendrik Hakenes / Martin Peitz
}

April 2008

Max Planck Institute for Research on Collective Goods, Kurt-Schumacher-Str. 10, D-53113 Bonn http://www.coll.mpg.de 


\title{
Umbrella Branding and External Certification*
}

\author{
Hendrik Hakenes ${ }^{\dagger}$ \\ Max Planck Institute, Bonn \\ University of Hannover
}

\author{
Martin Peitz \\ University of Mannheim \\ CEPR, CESifo, ENCORE, and ZEW
}

April 2, 2008

\begin{abstract}
In a market environment with random detection of product quality, a firm can employ umbrella branding as a strategy to convince consumers of the high quality of its products. Alternatively, a firm can rely on external certification of the quality of one or both of its products. We characterize equilibria in which umbrella branding fully or partially substitutes for external certification. We also show that the potential to signal quality is improved if consumers condition their beliefs on the source of information, namely whether information comes from external certification or from random detection.
\end{abstract}

Keywords: Umbrella branding, certification, signalling.

JEL-Classification: L14, L15, M37, D82.

\footnotetext{
*We received very helpful comments from an associate editor and two referees of the European Economic Review.

†Institute of Financial Economics, University of Hannover, Königsworther Platz 1, 30167 Hannover, Germany, hakenes@fmt.uni-hannover.de.

${ }^{\ddagger}$ Department of Economics, University of Mannheim, 68131 Mannheim, Germany, Martin.Peitz@googlemail.com.
} 


\section{Introduction}

In this paper, we present an information-based theory of umbrella branding as a full or partial substitute to socially costly, external (or, equivalently, thirdparty) certification. We consider an adverse selection environment in which a firm holds private information about the product quality of its two products and in which the asymmetric information problem is severe from society's point of view, in the sense that it is socially desirable to have high-quality products on the market, whereas it is socially undesirable to have low-quality products on the market. Certification of product quality is a viable option for a firm to reveal high product quality, but it is costly both from a private and a social point of view. However, a firm with broad abilities, i. e., which is able to produce two different high-quality products, may fully or partially avoid costly external certification by the use of umbrella branding. A firm with narrow abilities, i.e., which is able to produce only one high-quality product, must resort to external certification. We are able to capture these results in a simple one-period model, assuming that prior to purchase there is a positive probability that product quality will be revealed to all consumers (e.g., due to random inspections by a public authority).

For illustration, consider the market for bottled water in Europe. Taking a look at major European countries, we observe that many products are certified by an external laboratory. For instance, in Germany, the company Fresenius acts as an external certifier for most German producers. Fresenius regularly checks the water quality, and its analysis of water ingredients (in particular, minerals) is printed on the bottle. However, recently international companies such as Coca-Cola and Nestlé have entered the markets with their products Bonaqa and Aquarel, respectively. Bonaqa is then sold, for example, in vending machines together with other Coca-Cola products; Aquarel is sold explicitly under the Nestlé brand. While Bonaqa provides minimum information on ingredients (without reference), Nestlé does not provide any information. On its UK web site, it merely says: "The stringent controls set out by Nestlé guarantee the high quality of Nestlé Aquarel." ${ }^{1}$ Both companies

\footnotetext{
${ }^{1}$ See http://www.nestle-aquarel.com/uk/a-1_eau_source_naturelle.htm, checked June 25, 2007. Similar statements are found for other countries in their local languages.

According to EU definitions, Bonaqa is a table water and Aquarel a spring water, whereas other producers typically sell mineral waters. Although there are clear criteria to distinguish between these kinds of water, average consumers appear to consider that they belong to the same product category. By 2006, Bonaqa has established itself as a leading
} 
refrain from the use of an external certifier and implicitly or explicitly sell the product under an umbrella brand. Note that consumers may also obtain information about product quality through (random) detection, e.g., via tests published by the nonprofit organization Stiftung Warentest: in 2002, it published a quality index for 29 mineral waters that were sold in Germany. Since there are more than 200 producers of mineral waters in Germany and tests are not repeated regularly, this gives rise to a positive probability that product quality is detected before purchase. ${ }^{2}$

Umbrella branding is a frequently-used business practice that has received wide attention in the academic and nonacademic business literature. ${ }^{3}$ The general feature in an asymmetric information environment is that umbrella branding allows consumers to correlate beliefs. The use of umbrella branding and, when available, information regarding one product are used to update beliefs about the quality of other existing or future products for which this information is lacking. The existing economics literature has looked at a variety of moral hazard (Choi, 1998; Andersson, 2002; Hakenes and Peitz, 2008; Cabral, 2007) and adverse selection environments (Wernerfelt, 1988; Cabral, 2000; Miklós-Thal, 2007). ${ }^{4}$ In all these papers umbrella branding is the only signalling strategy available to the firm. Our paper is complementary to these papers in that we consider a market in which an alternative "signalling" strategy, namely costly external certification, is readily available to the firm and can reveal product quality to consumers. With external certification, the trivial reason that signalling works is because the quality of a product is fully revealed to consumers by a certifying expert, whose verdict

brand in the market for table and mineral waters in Germany (as, e.g., documented in Stern trend profile 04/06, published by the German magazine Stern).

${ }^{2}$ As another illustration, we can take the organic food industry in Germany, where some producers rely on external certification through, e.g., Demeter or Bioland, while others use their umbrella brand as an attempt to convince consumers of their quality. Both strategies can be understood as an attempt to convince consumers that quality is above the standards that are required by the European Union. In addition, there are random checks in the form of tests published by magazines such as Ökotest.

${ }^{3} \mathrm{~A}$ number of empirical papers (with experimental as well as field data) are broadly consistent with the view that umbrella branding allows a firm to solve an asymmetric information problem. For empirical evidence (with field data) see e. g. Erdem (1998) and Balachander and Ghose (2003). For experimental evidence see e.g. Aaker and Keller (1990).

${ }^{4}$ Some recent work looks at additional issues, e.g. Cai and Obara (2006) at horizontal integration and Dana and Spier (2006) at bundling. 
is assumed to be beyond doubt. But when does umbrella branding provide "certification" in such an environment, and can it be a substitute for external certification? Clearly, direct costs involved in the use of umbrella branding must be lower than those for external certification. But is this sufficient? Or, despite its lower costs, does umbrella branding lose its signalling potential in an environment in which external certification is available? ${ }^{5}$ This paper makes three points.

First, for a firm that produces two high-quality goods, umbrella branding can be the profit-maximizing strategy. One type of equilibrium consists of a firm with two high-quality products using umbrella branding to fully substitute for external certification. We show that the umbrella branding strategy is not profitable for other firms. The reason is that, since there is a positive detection probability, umbrella branding allows consumers to use negative information they receive on one product when forming their posterior belief about the quality of the other product. ${ }^{6}$ Therefore, a firm with one highand one low-quality product obtains higher profits if it does not use umbrella branding but externally certifies its high-quality product.

Second, under certain parameter constellations, there are equilibria with partial certification. Here, the certified product serves as an anchor for the non-certified product under the umbrella brand. Imitation by a firm that also has a low-quality product is not profitable if the detection probability is sufficiently high. In this environment, there are no reputation feed-back effects; this contrasts with an equilibrium in which umbrella branding works as a signal absent certification. Still, there is a role for umbrella branding, since external certification costs can at least partly be avoided, presuming that the use of umbrella branding is costly.

Third, the signalling potential of umbrella branding is improved if consumers condition their beliefs on the source of information they receive. There are two sources of information: the deliberate decision by the firm to certify its product, which reveals quality with probability 1, and (if cer-

\footnotetext{
${ }^{5}$ By comparing two different marketing strategies, namely external certification and umbrella branding, our paper contributes to the literature on the design of marketing practice and its allocative consequences (see Wernerfelt, 1994). For an informal discussion in the context of the food industry, see Sporleder and Goldsmith (2001).

${ }^{6}$ To support umbrella branding as a signal, the use of umbrella branding has to be costly in our base model (see Section 4). However, as is shown in Section 5, under additional conditioning of consumer beliefs umbrella branding may be a signal of product quality, even if its use is associated with lower costs than selling products under separate brands.
} 
tification is not used) the random detection of quality, which reveals quality with positive probability strictly less than 1 . But what is the motivation for a firm to certify one of its products under umbrella branding if consumers believe that umbrella branding on its own is regarded as a quality signal? It must mean that the firm wants to prevent the product that is detected to be of low quality from having a negative impact on the perception of the other product's quality. This means consumers should believe that a firm that certifies one product under umbrella branding must have something to hide, namely that the other product is of low quality. Under such beliefs, the signalling potential of umbrella branding (as a full substitute for external certification) is improved. Here, signalling is even compatible with umbrella branding being costless or bringing some fixed benefit.

We would also like to mention another feature of our model framework that distinguishes it from the rest of the literature (in addition to the possibility of external certification). All previous work on umbrella branding as a signal of product quality considers a dynamic setting. Either a multi-period game is analyzed, in which the firm is committed to constant quality for a product in all periods, or an infinite-horizon model is considered in which the signalling result relies on the use of non-Markovian supergame strategies. By introducing initial detection probabilities, we essentially collapse a twoperiod model into a single period. This way, we can provide a meaningful analysis within a one-period model and it is immaterial whether consumers observe quality after consumption; our analysis thus also applies to credence goods whose quality, however, can be observed by third parties (and the firm itself).

The plan of the paper is as follows. Section 2 presents the model. Section 3 provides preliminary results on the role of external certification, when umbrella branding is not available, and of umbrella branding, when external certification is not available. Section 4 analyzes umbrella branding when consumers do not distinguish where their information about product quality comes from. Section 5 extends the analysis to the case where consumer beliefs can be conditioned on the source of information. Section 6 concludes.

\section{The Model}

We provide a particularly simple model that can address issues of umbrella branding. Consider a model with two products of potentially different quali- 
ties. Qualities are described by numbers $\theta^{H}$ and $\theta^{L}$, measuring the willingness to pay of all consumers. By definition, consumers are willing to pay more for high than for low quality, $\theta^{H}>\theta^{L}$. Qualities, viewed as random variables, are assumed to be independent across products: Each product is of high quality with probability $p$. The realized product quality is observed by the firm but not always by consumers. To be precise, after the firm has taken its strategic decisions, the product is tested with probability $\delta$ by a third party (e.g., a nonprofit organization or a private company such as a magazine that reports quality tests), in which case quality realization is truthfully communicated to consumers. ${ }^{7}$ Before these tests are performed, the firm has to take several decisions. It decides which products to offer in the market. It may not want to offer a low-quality product on the market because the revenues from selling low quality may not recover the sunk cost $f$. In addition, the firm can go to an external certifier who truthfully reveals quality to consumers. We do not explicitly model the behavior of the external certifier, but simply assume that a high-quality firm that pays $c$ for a product reveals the quality of this product to consumers. ${ }^{8}$

The cost $c$ can alternatively be interpreted as the cost of a high-quality firm to provide a warranty - note that even a perfectly functioning product may trigger these costs if there is a moral hazard problem on the consumer side and the firm cannot prove that the malfunctioning of a product is due to inappropriate use. The warranty works as a quality signal. If providing a warranty is prohibitively costly for a low-quality product, the formal analysis is the same (see also our conclusion).

Certification of low quality is never an attractive option. Alternatively, or on top of certification, the firm can sell its products under an umbrella

\footnotetext{
${ }^{7}$ In several countries the results of product tests are published for a variety of products (e. g., in the U.S., Consumer Reports is published by the nonprofit organization Consumers Union). This corresponds to random detection by consumers because only a number of product categories (and within each category not necessarily all products) are covered by these tests. Note that in our model any detection provides full information about the product. In spite of this assumption, we are able to show that there is a role for umbrella branding. This is related to the issue of observability of quality in multi-period settings, where Wernerfelt (1988) assumes that a failure perfectly reveals that the product is of low quality, in contrast to Miklós-Thal (2007), where it is only an imperfect signal. To support umbrella branding as a quality signal, the former requires that umbrella branding is costly (as do we), whereas the latter does not.

${ }^{8}$ For an explicit model of external certification see Biglaiser (1993).
} 
brand at a cost $k .{ }^{9}$ Umbrella branding can here be understood as an attempt to certify one or both products without the help of an external certifier. We assume that $k<2 c$. Otherwise, a firm with high-quality products weakly prefers to certify the quality for both, rather than to put them under the costly umbrella. We present a one-period model so that issues of commitment are successfully eliminated from the analysis.

The sequence of moves can be described as follows:

Stage 1: Nature chooses the quality of both products as independent draws from a pool in which high quality occurs with probability $p$. The product qualities are observed by the firm but not by consumers.

Stage 2: The firm decides which products to offer on the market and pays the associated fixed cost per product $f$. It also decides whether to use umbrella branding at a cost $k$ and which (high-quality) product, if any, to certify at a cost $c$.

Stage 3: Consumers observe whether products are sold under an umbrella brand. They also observe the true quality of a product with probability 1 if it is certified, and with detection probability $\delta$ otherwise (where the underlying random variables are independent across products). Consumers update their beliefs and bid for the two products.

We analyze perfect Bayesian equilibria (PBE) of this game. In order to avoid the issue of price signalling, we introduce bidding by consumers and assume that there is excess demand for the product. In particular, we assume that there is mass 1 for each product that is put on the market and that there is a mass of consumers strictly greater than one. Thus consumers simply bid their expected surplus. Alternatively, if the firm sets prices for each product at stage 2, our analysis characterizes equilibria in which the firm extracts the full expected surplus from consumers. ${ }^{10}$

In this model we want to highlight four assumptions, which contain parameter restrictions and define the market environment of interest. First, we assume that externally certified high quality is viable in the market.

Assumption $1 \theta^{H}-c-f>0$.

\footnotetext{
${ }^{9}$ Wernerfelt (1988) argues that $k$ is often positive because a brand's image becomes diluted as different products are sold under the same brand. See however Section 4 in which $k$ can be of any sign.

${ }^{10}$ Full surplus extraction has also been assumed by Tadelis (1999) in a different context and Cabral (2000), Hakenes and Peitz (2008), and Miklós-Thal (2007) in the context of umbrella branding.
} 
Thus, in the absence of umbrella branding (i. e., if products are sold separately under different brands), a high-quality firm can certify its products and obtain strictly positive profits (see Section 3.1). Assumption 2 states that certification dominates non-certification if, in the absence of certification, products are believed to be of low quality (provided there is no other evidence), i. e., $\delta \theta^{H}+(1-\delta) \theta^{L}-f<\theta^{H}-c-f$.

Assumption $2(1-\delta)\left(\theta^{H}-\theta^{L}\right)>c$.

In a separating equilibrium, a single-product firm then always (externally) certifies high quality. The motivation for our first two assumptions is that we are interested in market environments in which we would observe external certification in the absence of the availability of umbrella branding; we want to understand the conditions under which umbrella branding can play the role of a quality signal. Third, we assume that low-quality provision is socially undesirable.

Assumption $3 \theta^{L}-f<0$.

Here, $\theta^{L}-f$ are also the profits that accrue to a low-quality product under full information. Hence, in a separating equilibrium, a low-quality firm prefers not to be active. The motivation for our third assumption is that we want to analyze an environment in which separation entails the desirable welfare property that low-quality products do not enter the market. However, a low-quality firm that is thought to produce high quality still makes positive profits. Otherwise, there would not exist an asymmetric information problem, and thus no rationale for certification, because a low-quality firm would never enter the market in the first place. This is stated as our fourth assumption.

Assumption $4 \delta \theta^{L}+(1-\delta) \theta^{H}-f>0$.

Throughout the analysis all four assumptions are supposed to be satisfied. Assumptions 1 and 2 are of course only relevant in markets in which certification is available and thus do not apply to Section 3.2.

In the presence of asymmetric information, we introduce consumer beliefs. For each product, the consumers may know that the product is of high or low quality or they may not know the quality. Thus we have the information partition $\left\{\left\{\theta^{H}\right\},\left\{\theta^{L}\right\},\left\{\theta^{H}, \theta^{L}\right\}\right\}$. Information with respect to product 
$i$, denoted by $I_{i}$, is then described by an element from this set. In addition, consumers observe whether umbrella branding is used. If a product is sold under an umbrella brand we write $u=1$, otherwise we write $u=0$. Posterior beliefs about product $i$ are then $b\left(\theta_{i} \mid u, I_{i}, I_{j}\right) \in[0,1]$, the perceived probability that this product is of high quality where $i, j=1,2, i \neq j, u \in\{0,1\}$, $I_{j} \in\left\{\left\{\theta^{H}\right\},\left\{\theta^{L}\right\},\left\{\theta^{H}, \theta^{L}\right\}\right\}$. Clearly, if a product's high quality has been certified (or its quality detected), consumers are convinced that this product has high quality, i.e. $b\left(\theta_{i} \mid u, I_{i}=\left\{\theta^{H}\right\}, I_{j}\right)=1$. Also, if a product is not sold under an umbrella brand beliefs must be constant in $I_{j}$. Note that a consumer may, in addition, condition her beliefs on the way she has received the information, that is, whether the firm actively used external certification or, after the release of the product, its quality was detected due to random quality checks by an outside party. We will analyze the relevance of this distinction in Section 5.

\section{Preliminary Results}

\subsection{Analysis in the Absence of Umbrella Branding}

In the absence of umbrella branding, consumers cannot correlate beliefs because they do not know which products are produced by the same firm. Because of assumptions 2 and 4, costly external certification solves the asymmetric information problem even in the absence of umbrella branding.

Remark 1 Suppose that the firm cannot use umbrella branding. In any separating equilibrium a high-quality product enters the market and is certified, and a low-quality product does not enter. ${ }^{11}$

However, compared to the first-best alternative (which is implemented under full information), we observe that certification generates social costs, since resources are used in the certification process (for simplicity, we can assume that private costs are equal to social costs of certification). As we will show, umbrella branding provides a multi-product firm with an instrument to transmit information to consumers without the need to invoke a costly external certification process for one or both of its products. We consider

\footnotetext{
${ }^{11}$ Note that there may exist pooling equilibria which give expected profit $2\left(p \theta^{H}+(1-\right.$ p) $\left.\theta^{L}-f\right)$. Hence the above separating is the unique Bayesian equilibrium if and only if $\theta^{H}-f-c>2\left(p \theta^{H}+(1-p) \theta^{L}-f\right)$. This is equivalent to $2(1-p)\left(\theta^{H}-\theta^{L}\right)>\theta^{H}-f+c$.
} 
this equilibrium the benchmark against which to compare the equilibria with umbrella branding.

\subsection{Analysis in the Absence of Certification}

As another case, one may want to look at the signalling role of umbrella branding in the absence of external certification. This kind of environment has been explored by the previous literature in models different from ours. Hence, let us analyze our model under the restriction that certification is not an option at stage 2 .

Suppose that umbrella branding may signal product quality and is used by a firm with two high-quality products but not by a firm of a different type. Then a firm with only one high-quality product cannot distinguish itself from a firm with two low-quality products in the event that product quality is not detected. We will now provide conditions under which entry with this kind of (partial) pooling is profitable and only a firm of type $\left(\theta^{H}, \theta^{H}\right)$ sells its products under an umbrella brand.

In the candidate equilibrium, a firm with two high-quality products uses umbrella branding and all other types enter but do not use umbrella branding and sell each product under a separate brand (alternatively we could provide conditions under which any firm of a type other than $\left(\theta^{H}, \theta^{H}\right)$ does not enter). A firm belongs to this latter group with probability $2 p(1-p)+(1-p)^{2}=$ $1-p^{2}$. Since the unconditional probability that a high-quality product is not sold under an umbrella brand is $p(1-p)$, we have that $p(1-p) /\left(1-p^{2}\right)=$ $p /(1+p)$ is the probability that a product is of high quality if it is sold under a separate brand. Correspondingly, $1 /(1+p)$ is the probability that a product is of low quality if it is sold under a separate brand. Along the equilibrium path we thus have the following conditional beliefs: $b\left(\theta_{i} \mid u=\right.$ $\left.0, I_{i}=\left\{\theta^{H}, \theta^{L}\right\}, I_{j}\right)=1 /(1+p)$ for all $I_{j}$. In addition, two products that are sold under an umbrella brand are believed to be of high quality unless there is contradictory evidence, i. e., $b\left(\theta_{i} \mid u=1, I_{i}=\left\{\theta^{H}, \theta^{L}\right\}, I_{j}=\left\{\theta^{H}, \theta^{L}\right\}\right)=$ $b\left(\theta_{i} \mid u=1, I_{i}=\left\{\theta^{H}, \theta^{L}\right\}, I_{j}=\left\{\theta^{H}\right\}\right)=1$. To complete the belief system, we specify out-of-equilibrium beliefs that support this equilibrium. Suppose that when consumers observe low quality for a product within an umbrella brand, they are pessimistic and believe that the quality of the other product is also low, $b\left(\theta_{i} \mid u=1, I_{i}=\left\{\theta^{H}, \theta^{L}\right\}, I_{j}=\left\{\theta^{L}\right\}\right)=0$.

We now provide a condition for a firm with one high- and one low-quality good to enter. If a firm enters with two unbranded products and the quali- 
ties of both products are not detected, its expected profits per product are $\frac{p}{1+p} \theta^{H}+\frac{1}{1+p} \theta^{L}$ provided that types $\left(\theta^{H}, \theta^{L}\right),\left(\theta^{L}, \theta^{H}\right)$, and $\left(\theta^{L}, \theta^{L}\right)$ pool. Therefore, a firm of type $\left(\theta^{H}, \theta^{L}\right)$ or $\left(\theta^{L}, \theta^{H}\right)$ makes expected profits of $\delta\left(\theta^{H}-f\right)+2(1-\delta)\left(\frac{p}{1+p} \theta^{H}+\frac{1}{1+p} \theta^{L}-f\right)+\delta\left(\theta^{L}-f\right)$. A firm of type $\left(\theta^{L}, \theta^{L}\right)$ obtains lower profits as both of its products can be of low quality, $2 \delta\left(\theta^{L}-f\right)+2(1-\delta)\left(\frac{p}{1+p} \theta^{H}+\frac{1}{1+p} \theta^{L}-f\right)$. Participation of a firm of type $\left(\theta^{L}, \theta^{L}\right)$ is profitable if and only if

$$
(1-\delta) \frac{p}{1+p}\left(\theta^{H}-f\right) \geq \frac{1+\delta p}{1+p}\left(f-\theta^{L}\right)
$$

This condition is satisfied if $f$ is sufficiently close to $\theta^{L}$. Hence, if (1) holds, a firm with two low-quality products enters, provided it does not use an umbrella. This implies already that firms of type $\left(\theta^{H}, \theta^{L}\right)$ or $\left(\theta^{L}, \theta^{H}\right)$ also enter. In addition, we have to show that in equilibrium, firms of type $\left(\theta^{H}, \theta^{L}\right)$, $\left(\theta^{L}, \theta^{H}\right)$, or $\left(\theta^{L}, \theta^{L}\right)$ cannot make higher expected profits by selling their products under an umbrella brand. Consider first a firm of type $\left(\theta^{H}, \theta^{L}\right)$ or $\left(\theta^{L}, \theta^{H}\right)$. With probability $1-\delta$, the low quality is not discovered by consumers, in which case consumers believe that both products are of high quality. Profits in this case are $2\left(\theta^{H}-f\right)$. With probability $\delta^{2}$, the quality of both products is observed. Profits in this case are $\theta^{H}+\theta^{L}-2 f$. With the remaining probability $\delta(1-\delta)$, consumers only obtain the information that one of the products under the umbrella is of low quality. In this case we have imposed out-of-equilibrium beliefs that the other product is also of low quality. Profits are then $2\left(\theta^{L}-f\right)$. Expected deviation profits are therefore $(1-\delta) 2\left(\theta^{H}-f\right)+\delta^{2}\left(\theta^{H}+\theta^{L}-2 f\right)+\delta(1-\delta) 2\left(\theta^{L}-f\right)-k$. These deviation profits have to be lower than profits along the proposed equilibrium path. Hence, a deviation is not profitable if and only if

$$
\frac{1-\delta}{1+p}(2-\delta-p \delta)\left(\theta^{H}-\theta^{L}\right)-k \leq 0
$$

is satisfied. Second, consider a firm of type $\left(\theta^{L}, \theta^{L}\right)$. Expected deviation profits are $(1-\delta)^{2} 2\left(\theta^{H}-f\right)+\left(1-(1-\delta)^{2}\right) 2\left(\theta^{L}-f\right)-k$. These deviation profits have to be lower than profits along the proposed equilibrium path. Hence, a deviation is not profitable if and only if

$$
\frac{1-\delta}{1+p}(1-\delta-p \delta)\left(\theta^{H}-\theta^{L}\right)-\frac{k}{2} \leq 0
$$


This inequality is implied by (2). Finally, a firm of type $\left(\theta^{H}, \theta^{H}\right)$ must have an incentive to actually use the umbrella. The non-deviation constraint of the firm of type $\left(\theta^{H}, \theta^{H}\right)$ is

$$
2\left(\theta^{H}-f\right)-k \geq 2 \delta\left(\theta^{H}-f\right)+2(1-\delta)\left(\frac{p}{1+p} \theta^{H}+\frac{1}{1+p} \theta^{L}-f\right)
$$

This condition can be rewritten as

$$
\frac{1-\delta}{1+p}\left(\theta^{H}-\theta^{L}\right)-\frac{k}{2} \geq 0
$$

We can thus state the following remark.

Remark 2 Suppose that the firm cannot use external certification and suppose conditions (1), (2), and (3) are satisfied. Then there exist separating equilibria in which a firm with two high-quality products uses umbrella branding as a signal of product quality, and all other firm types sell their products under separate brands.

Note that conditions (2) and (3) have a similar structure and there exist parameter constellations which satisfy both of them. Condition (1) is of a different form and is satisfied under some parameters from the set that satisfy (2) and (3). In Appendix A.1, we show that the equilibrium satisfies the intuitive criterion.

We also want to point out that there may be another type of equilibrium with umbrella branding, namely one in which types $\left(\theta^{H}, \theta^{H}\right),\left(\theta^{H}, \theta^{L}\right)$, and $\left(\theta^{L}, \theta^{H}\right)$ pool under the umbrella. In Appendix A.2, we analyze this equilibrium and provide conditions for existence. In the following section we introduce certification; there we do not assume that any of the above conditions is satisfied.

\section{Branding as a Substitute to Certification}

In many real-world markets most consumers become informed about realized quality through word-of-mouth. In such markets, it seems realistic to assume that the vast majority of consumers is unaware of the original source of information, namely if the firm externally certified its product or if the product's quality was revealed through, e.g., Consumer Reports in the U.S. 
or Stiftung Warentest in Germany. In this case, consumers cannot condition their beliefs on the original source of information - the reverse hypothesis will be analyzed in the next section, where consumers can condition their beliefs on the source of information.

In the present section, we will first analyze the parameter constellations under which umbrella branding can be used as a signal of product quality and thus fully substitutes for external certification. We will then analyze the situation in which the firm certifies one product and uses umbrella branding as a signal of high quality for the other product. Clearly, there is also an equilibrium in which umbrella branding does not play any signalling role. Since we are interested in equilibria with umbrella branding, we ignore this possibility in the remainder.

\subsection{Branding as a Full Substitute to Certification}

For the firm to use umbrella branding as a signal, suppose that consumers believe that absent contradictory evidence, umbrella branding is associated with high quality for both products (with probability 1 ). This means that consumers hold beliefs $b\left(\theta_{i} \mid u=1, I_{i}=\left\{\theta^{H}, \theta^{L}\right\}, I_{j}=\left\{\theta^{H}, \theta^{L}\right\}\right)=1$ and $b\left(\theta_{i} \mid u=1, I_{i}=\left\{\theta^{H}, \theta^{L}\right\}, I_{j}=\left\{\theta^{H}\right\}\right)=1$. If consumers obtain the information that one product is of low quality and the quality of the other product remains unknown, they are assumed to form beliefs that the other product is also of low quality, i. e., $b\left(\theta_{i} \mid u=1, I_{i}=\left\{\theta^{H}, \theta^{L}\right\}, I_{j}=\left\{\theta^{L}\right\}\right)=0$.

In the candidate equilibrium that we consider, a firm of type $\left(\theta^{H}, \theta^{H}\right)$ decides to use umbrella branding and obtains profits $2 \theta^{H}-2 f-k$, where $k$ is the cost of using umbrella branding. Umbrella branding is superior to external certification as the firm can save on the external certification costs for each of its products.

By contrast, a firm of type $\left(\theta^{H}, \theta^{L}\right)$ or $\left(\theta^{L}, \theta^{H}\right)$ does not use umbrella branding in equilibrium. It certifies its high-quality product and does not put the other, low-quality product on the market. Its profits are thus $\theta^{H}-c-f$, which is positive according to assumption 1 . Thus a firm that is not able to put two high-quality products on the market refrains from the use of umbrella branding and externally certifies its high-quality product. A firm of type $\left(\theta^{L}, \theta^{L}\right)$ does not offer any of its products on the market and therefore makes zero profits.

To support this equilibrium we have to show that there are no profitable deviations for any type. This will lead to parameter restrictions under which 
umbrella branding can fully substitute certification for a firm of type $\left(\theta^{H}, \theta^{H}\right)$. There are three potentially profitable deviations, two for types $\left(\theta^{H}, \theta^{L}\right)$ and $\left(\theta^{L}, \theta^{H}\right)$ and one for type $\left(\theta^{L}, \theta^{L}\right)$. We have to show that deviations are not profitable. The relevant deviation we have to consider is the use of umbrella branding (by a firm with low-quality products, either with or without certifying its high-quality product). Consider first the use of umbrella branding on its own. As derived in the previous section, expected deviation profits are

$$
(1-\delta) 2\left(\theta^{H}-f\right)+\delta^{2}\left(\theta^{H}+\theta^{L}-2 f\right)+\delta(1-\delta) 2\left(\theta^{L}-f\right)-k .
$$

These deviation profits have to be less than $\theta^{H}-c-f$. The corresponding inequality can be rewritten as

$$
\delta(2-\delta)\left(f-\theta^{L}\right) \geq(1-\delta)^{2}\left(\theta^{H}-f\right)+c-k .
$$

Since $c<\theta^{H}-f$ by assumption, a sufficient condition is that $\delta(2-\delta)(f-$ $\left.\theta^{L}\right) \geq\left[1+(1-\delta)^{2}\right]\left(\theta^{H}-f\right)-k$.

Mimicking the $\left(\theta^{H}, \theta^{H}\right)$ type is successful unless low quality is detected. Hence, with probability $1-\delta$, the low-quality product is believed to be of high quality and thus is sold at price $\theta^{H}$. However, with probability $\delta$, low quality is detected. In this case, the firm does not recover its fixed cost on the low-quality product and makes a loss on this product. In addition, if low quality but not high quality is detected (which happens with probability $\delta(1-\delta))$ the firm suffers from a negative reputation feed-back because also its high-quality product is believed to be of low quality.

By certifying its high-quality product, the firm can avoid the negative reputation feed-back effect. We therefore turn to an alternative deviation of a firm of type $\left(\theta^{H}, \theta^{L}\right)$, according to which it certifies its high-quality product and uses umbrella branding in an attempt to convince consumers that the other product is of high quality. Suppose that, absent contradictory evidence, consumers form such beliefs. Then with probability $1-\delta$, consumers do not find contradictory evidence and the firm makes profits $\left(\theta^{H}-c-f\right)+\left(\theta^{H}-f\right)-$ $k$. However, with probability $\delta$, the low-quality product is unmasked, and profits are $\left(\theta^{H}-c-f\right)+\left(\theta^{L}-f\right)-k$. The deviation is therefore unprofitable if $\theta^{H}-c-f \geq(1-\delta)\left[\left(\theta^{H}-c-f\right)+\left(\theta^{H}-f\right)\right]+\delta\left[\left(\theta^{H}-c-f\right)+\left(\theta^{L}-f\right)\right]-k$, which is equivalent to

$$
\delta\left(f-\theta^{L}\right) \geq(1-\delta)\left(\theta^{H}-f\right)-k .
$$

We can also write this condition as $\delta \theta^{L}+(1-\delta) \theta^{H}-f \leq k$. Remember that an asymmetric information problem only exists if assumption 4 is satisfied, 
i. e., if $\delta \theta^{L}+(1-\delta) \theta^{H}-f>0$. This shows that a necessary condition for umbrella branding to work as a signal is that it is costly. Otherwise, a firm with one high-quality and one low-quality product can certify its high-quality product under an umbrella brand. Such a deviation would be profitable because, with probability $1-\delta$, the low-quality product would falsely be perceived to be of high quality, and there could be no negative reputation feed-back on the high-quality product, because of its certification.

The only possibly profit-increasing deviation for a firm of type $\left(\theta^{L}, \theta^{L}\right)$ is to offer both products on the market and to use umbrella branding. With probability $(1-\delta)^{2}$, the firm can masquerade as a high-quality producer and make profits $2\left(\theta^{H}-f\right)$. Whenever at least one of the two products is unmasked to be of low quality consumers believe that both products are of low quality. This happens with probability $1-(1-\delta)^{2}$ and profits are $2\left(\theta^{L}-f\right)$. Hence, deviation profits

$$
(1-\delta)^{2} 2\left(\theta^{H}-f\right)+\left[1-(1-\delta)^{2}\right] 2\left(\theta^{L}-f\right)-k
$$

have to be non-positive. This is equivalent to

$$
2 \delta(2-\delta)\left(f-\theta^{L}\right) \geq 2(1-\delta)^{2}\left(\theta^{H}-f\right)-k
$$

For $k \in[0,2 c]$, this inequality is implied by condition (4). We thus have established the conditions under which umbrella branding can fully substitute for external certification.

Proposition 1 Suppose conditions (4) and (5) are satisfied. For $k \in(0,2 c)$ there is a PBE in which umbrella branding signals the high quality of both products. Umbrella branding fully substitutes for external certification.

To illustrate that these conditions are not mutually exclusive, first note that both conditions have the structure $\alpha\left(f-\theta^{L}\right) \geq \gamma+\beta\left(\theta^{H}-f\right)$. In the special case $\delta=1 / 2$, condition (4) becomes $(3 / 4)\left(f-\theta^{L}\right) \geq(1 / 4)\left(\theta^{H}-\right.$ $f)+c-k$ and (5) becomes $(1 / 2)\left(f-\theta^{L}\right) \geq(1 / 2)\left(\theta^{H}-f\right)-k$. To satisfy assumptions 1 to 4 , parameters must satisfy $\theta^{H}-c-f>0, \theta^{H}-f>$ $f-\theta^{L}>0$, and $\theta^{H}-\theta^{L}>c$. As a particular example take $\theta^{H}=1, \theta^{L}=0.1$, $c=k=0.1, \delta=0.5$ and $f=0.5$.

\subsection{Branding as a Partial Substitute to Certification}

Suppose now that consumers do not believe in the signalling role of umbrella branding unless one of the two products is revealed to be of high quality, 
i. e., $b\left(\theta_{i} \mid u=1, I_{i}=\left\{\theta^{H}, \theta^{L}\right\}, I_{j}=\left\{\theta^{H}\right\}\right)=1$, whereas $b\left(\theta_{i} \mid u=1, I_{i}=\right.$ $\left.\left\{\theta^{H}, \theta^{L}\right\}, I_{j}=\left\{\theta^{H}, \theta^{L}\right\}\right)=0$. Can there be an equilibrium such that the firm still uses umbrella branding as an attempt to signal high quality without certifying any of its two products? The answer is negative. Suppose that a firm with two high-quality products uses umbrella branding, but does not certify and that other types of firms do not use umbrella branding. Then with probability $(1-\delta)^{2}$ the quality of neither product will be revealed to consumers. In this case beliefs are not confirmed (consumers experience a positive surprise), so this cannot be part of a perfect Bayesian equilibrium.

There is a single equilibrium candidate under the above restrictions: The firm with two high-quality products uses umbrella branding and certifies one of the two products. Hence, the firm partially substitutes for external certification with umbrella branding. The firm with a single high-quality product - where the other product is of low quality - brings only this product to the market and certifies it. Low-quality products are not put on the market.

This result can indeed be supported as an equilibrium outcome under certain parameter constellations, as we will show next. Along the equilibrium path, the firm of type $\left(\theta_{1}, \theta_{2}\right)=\left(\theta^{H}, \theta^{H}\right)$ obtains profits $2 \theta^{H}-c-k-$ $2 f$. Clearly, for $k<c$, this dominates the choice to externally certify both products and to forego umbrella branding. Consider the deviation in which neither of the two products is certified. Its expected profits are then equal to $\left(1-(1-\delta)^{2}\right) 2 \theta^{H}+(1-\delta)^{2} 2 \theta^{L}-2 f-k$. This deviation is not profitable if

$$
2(1-\delta)^{2}\left(\theta^{H}-\theta^{L}\right) \geq c .
$$

None of the other deviations are ever profitable. Along the equilibrium path, the firm of type $\left(\theta_{i}, \theta_{j}\right)=\left(\theta^{H}, \theta^{L}\right)$ obtains profits $\theta^{H}-c-f$. Consider now the deviation to offer both products on the market, to certify high quality, and to use umbrella branding. Deviation profits are $\theta^{H}-c-f+(1-\delta)\left(\theta^{H}-\right.$ $f)+\delta\left(\theta^{L}-f\right)-k$. A deviation is not profitable if

$$
\delta\left(f-\theta^{L}\right) \geq(1-\delta)\left(\theta^{H}-f\right)-k,
$$

which is the case if the detection probability $\delta$ is sufficiently large. This condition is equivalent to condition (5). Finally, consider the deviation in which both products are offered on the market, the high-quality product is not certified, and umbrella branding is used. With probability $\delta(1-\delta)$, the quality of the high-quality product (but not that of the low-quality product) 
is revealed to consumers, and therefore consumers believe that both products are of high quality. With probability $\delta^{2}$, consumers become fully informed. Otherwise, they believe that both products are of low quality. Expected deviation profits are therefore $\delta(1-\delta) 2\left(\theta^{H}-f\right)+\delta^{2}\left(\theta^{H}+\theta^{L}-2 f\right)+(1-$ f) $2\left(\theta^{L}-f\right)-k$. This deviation is not profitable if

$$
(1-\delta)^{2}\left(\theta^{H}-\theta^{L}\right)+\left(f-\theta^{L}\right) \geq c-k .
$$

We thus have established the conditions under which umbrella branding can partially substitute for external certification.

Proposition 2 Suppose conditions (6), (7), and (8) are satisfied. Then for $k \in(0, c)$, there is a PBE in which umbrella branding, together with the external certification of one product, signals the high quality of the other product. Umbrella branding partially substitutes for external certification.

Let us argue that the conditions are mutually consistent. Two of the necessary conditions for this type of equilibrium provide an upper bound on the certification cost (that is different from the upper bound from assumption $\left.1, \theta^{H}-c-f>0\right)$. In addition, given certification of the high-quality product, a firm of type $\left(\theta^{H}, \theta^{L}\right)$ must not have an incentive to use umbrella branding, thus condition (7) must hold. To give an instance for consistency, let us consider again the special case $\delta=1 / 2$. In this case, condition (6) becomes $\left(\theta^{H}-\theta^{L}\right) / 2 \geq c$ which is the weak form of assumption 2 . Condition (8) becomes $\left(\theta^{H}-\theta^{L}\right) / 4+\left(f-\theta^{L}\right) \geq c-k$ and condition (7) becomes $(1 / 2)\left(f-\theta^{L}\right) \geq(1 / 2)\left(\theta^{H}-f\right)-k$. To satisfy assumptions 1,3 , and 4 , parameters must satisfy $\theta^{H}-c-f>0$ and $\theta^{H}-f>f-\theta^{L}>0$. The set of parameters that satisfy all these inequalities is non-empty. A particular example is the parameter constellation reported in the previous subsection with the only difference that $k$ must be smaller than $c$, e.g., $k=0.075$, so that there is a strict gain from using umbrella branding as a partial substitute to external certification.

Our final point is that we can make the case in favor of full substitution and against partial substitution based on a priori restrictions on admissible beliefs and the intuitive criterion (Cho and Kreps, 1987). Suppose that umbrella branding is a viable signalling strategy, i. e., (4) is satisfied. Let us now restrict beliefs under umbrella branding to have the following property (PC): Absent contradictory evidence, consumers believe that product quality is perfectly correlated when products are sold under an umbrella brand. This 
implies that consumers must hold out-of-equilibrium beliefs that a product of unknown quality must be of low quality if the other product under the umbrella is detected to be of low quality. Consider now equilibrium beliefs under partial substitution. Note that umbrella branding without certification is a zero probability event. This implies that the situation in which a consumer observes umbrella branding but none of the two qualities is observed occurs only off the equilibrium path. As we have seen in the previous subsection, the use of umbrella branding without certification is equilibrium-dominated for all firms other than type $\left(\theta^{H}, \theta^{H}\right)$, for all possible beliefs (under the restriction that property $\mathrm{PC}$ is satisfied). However, there exist beliefs that make a deviation to umbrella branding without certification profitable for type $\left(\theta^{H}, \theta^{H}\right)$. Therefore, following the forward induction argument inherent in the intuitive criterion, consumers should believe that such a deviation must come from type $\left(\theta^{H}, \theta^{H}\right)$. This destabilizes the equilibrium with partial substitution.

\section{Conditioning of Beliefs}

So far, we have implicitly assumed that consumers do not know the source of their information, and thus cannot condition beliefs on this source. In this section we assume that consumers learn whether the product information they receive is due to external certification (as a deliberate decision of the firm) or due to detection. Clearly, in our setup this is only relevant for a product whose high quality has been revealed. The belief function $b$ then includes two additional arguments, namely whether product 1 has been externally certified and whether product 2 has been externally certified. Denote these decisions by $x_{i} \in\{0,1\}$, where $x_{i}=1$ stands for the certification of product $i$. In a slight abuse of notation, we write beliefs as $b\left(\theta_{i} \mid u, x_{1}, x_{2}, I_{1}, I_{2}\right)$.

Why should the conditioning matter? A firm that uses umbrella branding and has one high- and one low-quality product may want to certify its high-quality product to avoid a reputation feed-back effect (consumers who detect the low-quality product, but not the high-quality product, could believe that also the undetected product is of low-quality). Note that a firm with two high-quality products does not share this concern and consequently does not certify one of its products. This argument provides a rationale for consumers to condition beliefs on the source of information. We will now 
show that umbrella branding can then be supported as a signal for a larger set of parameters under a particular belief system.

Take the following system of beliefs: If a separate brand is observed, then, in case of doubt, consumers believe products to be of low quality. If an umbrella brand is observed, beliefs have the following property: if consumers know that a product is of high quality (because of detection or external certification), we must have $b\left(\theta_{1} \mid u=1, x_{1}, x_{2}, I_{1}=\left\{\theta^{H}\right\}, I_{2}\right)=1$ for $x_{i} \in\{0,1\}$. If consumers do not have information on product 1 and if product 2 was not certified, they believe that product 1 must be of high quality, i.e., $b\left(\theta_{1} \mid u=1, x_{1}=0, x_{2}=0, I_{1}=\left\{\theta^{L}, \theta^{H}\right\}, I_{2}=\left\{\theta^{L}, \theta^{H}\right\}\right)=1$. This does not change if the other product is detected to be of high quality, $b\left(\theta_{1} \mid u=1, x_{1}=0, x_{2}=0, I_{1}=\left\{\theta^{L}, \theta^{H}\right\}, I_{2}=\left\{\theta^{H}\right\}\right)=1{ }^{12}$ However, if, instead, product 2 was certified, they believe that product 1 must be of low quality, i. e., $b\left(\theta_{1} \mid u=1, x_{1}=0, x_{2}=1, I_{1}=\left\{\theta^{L}, \theta^{H}\right\}, I_{2}=\left\{\theta^{H}\right\}\right)=0$; and correspondingly for product 2 . Then under which parameter conditions can the umbrella be supported as a signal of product quality?

As in Section 4.1, the relevant deviations to consider are those in which a firm of type $\left(\theta^{H}, \theta^{L}\right)$ uses umbrella branding on its own or in combination with the external certification of its high-quality product and in which a firm of type $\left(\theta^{L}, \theta^{L}\right)$ uses umbrella branding on its own. Equilibrium and deviation profits are the same as the ones reported in Section 4.1, with only one exception. This is the above described case in which a firm of type $\left(\theta^{H}, \theta^{L}\right)$ uses umbrella branding in combination with external certification. Here deviation profits are

$$
\left(\theta^{H}-c-f\right)+\left(\theta^{L}-f\right)-k
$$

which is strictly less than the deviation profits reported in Section 4.1 and, more importantly, which is necessarily strictly less than the profits along the postulated equilibrium path, $\theta^{H}-c-f$. The inequality even holds if umbrella branding is not costly. This implies that the set of parameters under which umbrella branding can serve as a signal is described by condition (4).

Proposition 3 Suppose that consumers can condition their beliefs on whether their information is due to external certification or detection and that condition (4) is satisfied. For $k \in(0,2 c)$ there is a PBE in which umbrella

\footnotetext{
${ }^{12} \mathrm{As}$ in the previous section, the detection of low quality of the other product is interpreted as bad news about the product under consideration, i. e., $b\left(\theta_{1} \mid u=1, x_{1}=0, x_{2}=\right.$ $\left.0, I_{1}=\left\{\theta^{L}, \theta^{H}\right\}, I_{2}=\left\{\theta^{L}\right\}\right)=0$.
} 
branding signals the high quality of both products. Umbrella branding fully substitutes for external certification.

The intuition for this result is that, in the presence of certification, consumers negatively correlate beliefs about product quality. Namely, a product of unknown quality is believed to be of low quality if it is sold together with a certified high-quality product under an umbrella brand. Consumers here "punish" certification of one of the products under umbrella branding, which makes umbrella branding, together with certification, a strategy that cannot be profit-maximizing.

In this setting it is possible that, even if umbrella branding is costless or carries a benefit, $k<0$ (e.g., because of economies-of-scope in advertising), umbrella branding can be supported as a signal of product quality. Condition (4) is met if $k \geq c+(1-\delta)^{2}\left(\theta^{H}-f\right)-\delta(2-\delta)\left(f-\theta^{L}\right)$. Take the same parameter constellation as in section 4.1 without fixing $k: \theta^{H}=1, \theta^{L}=0.1$, $c=0.1, \delta=0.5$ and $f=0.5$. In this example, condition (4) becomes $k \geq$ -0.075 . We have thus constructed a one-period model in which certification perfectly reveals product quality and still there is an information role for umbrella branding, even if it is not costly to use.

\section{Conclusion}

In many markets, firms have to choose between implicit quality promises and external or third-party certification. External certification can be seen as beyond doubt if it comes from a semi-public institution that works in the public interest, or if it comes from a private institution that does not put its reputation at stake. Implicit quality promises by the firm - this may be dubbed self-certification - appear more problematic, since they may lack credibility. In this paper we have shown that umbrella branding, interpreted as self-certification, can be a cost-efficient way to signal product quality. It can fully or partially substitute for external certification.

In a single-period model with positive detection probabilities for high and low quality, umbrella branding can fully substitute for external certification, provided that its use is costly. A firm may have to use umbrella branding, together with certification of one of its products, when consumers are skeptical about umbrella brands that do not include certified products. Here, the umbrella is used to convince consumers that information which comes from 
the certification of one of its products also shows that the non-certified product is of high quality. This is sustained as an equilibrium outcome because imitating is detected with some (sufficiently large) probability, and umbrella branding is costly. Note that since one of the products is certified, there is no reputation feed-back effect.

However, if consumers condition their beliefs on the source of information, certification of a product under an umbrella may be interpreted as an indication of the low quality of the other product. This improves the signalling potential of umbrella branding and makes the signalling argument compatible with umbrella branding bringing fixed benefits in the presence of external certification.

In our formal analysis, we have interpreted $c$ as the cost of external certification. As we have pointed out in the main text, we can alternatively interpret $c$ as the cost of extended warranties for high-quality producers (which may involve a social cost because of a moral hazard problem on the consumer side) under the assumption that such extended warranties are prohibitively costly for low-quality producers to apply for. Firms with a broad product portfolio may be able to avoid these costs $c$ with the help of umbrella branding. Interestingly, we observe that in the past, Japanese, and, more recently, South Korean producers entered European and the U.S. markets with extended warranties for cars and household appliances (and, initially, with a small product range), at the time when established manufacturers used umbrella branding but did not offer such extended warranties. Although our model does not capture dynamic aspects which are likely to be of relevance in the present example (such as, e.g., different degrees of previously accumulated reputation), our results are in line with the observation that producers with abilities in a small product range have to use instruments other than umbrella branding to convince consumers of high quality, whereas producers with broad abilities may be able to avoid the use of these costly alternatives.

\section{A Appendix}

\section{A.1 Equilibrium Refinement}

For a firm of type $\left(\theta^{L}, \theta^{L}\right)$, equilibrium profits are

$$
\pi^{*}\left(\theta^{L}, \theta^{L}\right)=2 \delta \theta^{L}+2(1-\delta)\left(\frac{p}{1+p} \theta^{H}+\frac{1}{1+p} \theta^{L}\right)-2 f .
$$


Recall that we have assumed the following out-of-equilibrium beliefs: when consumers observe that one product is of low quality, they believe that the other product is of high quality with probability 0 , i.e., $b\left(\theta_{i} \mid u=1, I_{i}=\right.$ $\left.\left\{\theta^{H}, \theta^{L}\right\}, I_{j}=\left\{\theta^{L}\right\}\right)=0$. For the equilibrium to satisfy the intuitive criterion by Cho and Kreps (1987), we have to show that there exist out-of-equilibrium beliefs that make a deviation to umbrella branding by $\left(\theta^{L}, \theta^{L}\right)$ profitable. Then the above-mentioned out-of-equilibrium beliefs cannot be ruled out by the intuitive criterion.

Consider the following out-of-equilibrium beliefs: consumers believe that an undetected product under the umbrella brand is of high quality with probability 1 even if the other product is known to be of low quality, $b\left(\theta_{i} \mid u=\right.$ $\left.1, I_{i}=\left\{\theta^{H}, \theta^{L}\right\}, I_{j}=\left\{\theta^{L}\right\}\right)=1$. Under these alternative out-of-equilibrium beliefs, a firm of type $\left(\theta^{L}, \theta^{L}\right)$ makes profits

$$
\begin{aligned}
& \delta^{2} 2 \theta^{L}+2 \delta(1-\delta)\left(\theta^{H}+\theta^{L}\right)+(1-\delta)^{2}\left(2 \theta^{H}\right)-2 f-k \\
= & 2 \delta \theta^{L}+2(1-\delta) \theta^{H}-2 f-k
\end{aligned}
$$

which is greater or equal to equilibrium profits $\pi^{*}\left(\theta^{L}, \theta^{L}\right)$ if and only if

$$
(1-\delta) \frac{1}{1+p}\left(\theta^{H}-\theta^{L}\right)-\frac{k}{2} \geq 0 .
$$

This inequality is identical to condition (3). Hence, there always exist outof-equilibrium beliefs that justify type $\left(\theta^{L}, \theta^{L}\right)$ 's deviation to use umbrella branding and we cannot exclude this type from the set of types on which consumers put positive probability in their beliefs given that $u=1$. The equilibrium therefore survives the intuitive criterion by Cho and Kreps (1987).

\section{A.2 Additional Equilibria}

In this section, we address the question whether there is an equilibrium where firms of types $\left(\theta^{H}, \theta^{H}\right),\left(\theta^{H}, \theta^{L}\right)$, and $\left(\theta^{L}, \theta^{H}\right)$ pool by all using an umbrella brand, with the according beliefs.

First, if the quality of none of the two products is detected, a consumer expects the quality of a product to be high with probability

$$
\frac{p^{2}+p(1-p)}{p^{2}+2 p(1-p)}=\frac{1}{2-p}
$$


which is greater than $p$ for all $p<1$. Second, if high quality is detected for one of the two products, the consumer expects the quality of the other product to be high with probability

$$
\frac{p^{2}}{p^{2}+p(1-p)}=p
$$

Hence, the expected quality for the other product increases if one product is detected to have low quality. Third, if low quality is detected for one of the two products, the consumer expects the quality of the other product to be high with probability 1 . As a consequence, the expected deviation profits of a firm of type $\left(\theta^{L}, \theta^{L}\right)$ selling under an umbrella brand would be

$$
\begin{aligned}
& \delta^{2} 2 \theta^{L}+2 \delta(1-\delta)\left(\theta^{L}+\theta^{H}\right) \\
+ & (1-\delta)^{2}\left(\frac{1}{2-p} 2 \theta^{H}+\frac{1-p}{2-p} 2 \theta^{L}\right)-k-2 f .
\end{aligned}
$$

In equilibrium, this expression must be negative. In addition, a firm of type $\left(\theta^{H}, \theta^{L}\right)$ must make positive expected profits, which leads to a condition of the form $\lambda_{1}\left(\theta^{H}-f\right)-k<\lambda_{2}\left(f-\theta^{L}\right)$ for some numbers $\lambda_{1}, \lambda_{2}$ that depend on the other parameters of the model.

The candidate equilibrium fails to be an equilibrium if the above expected deviation profits are positive, which is equivalent to

$$
\begin{aligned}
& 2 \frac{1-p}{2-p}\left((1-p)\left(1+\delta^{2}\right)+\delta p\right)\left(f-\theta^{L}\right) \\
< & 2(1-\delta)\left(\frac{1-\delta}{2-p}+\delta\right)\left(\theta^{H}-f\right)-k .
\end{aligned}
$$

In general, this inequality may or may not be satisfied.

\section{References}

[1] Aaker, D. A., and K. L. Keller (1990), Consumer Evaluations of Brand Extensions, Journal of Marketing, 54(1), 27-41.

[2] Andersson, F. (2002), Pooling Reputations. International Journal of Industrial Organization, 20(5), 715-730. 
[3] Balachander, S., and S. Ghose (2003), Reciprocal Spillover Effects: A Strategic Benefit of Brand Extensions, Journal of Marketing, 67(1), 413 .

[4] Biglaiser, G. (1993), Middlemen as Experts, Rand Journal of Economics, 24(2), 212-223.

[5] Cabral, L. (2000), Stretching Firm and Brand Reputation, RAND Journal of Economics, 31(4), 658-673.

[6] Cabral, L. (2007), Optimal Brand Umbrella Size, New York University, mimeo.

[7] Cai, H., and I. Obara (2006), Firm Reputation and Horizontal Integration, U.C.L.A., mimeo.

[8] Choi, J. P. (1997), Brand Extension and Informational Leverage, Review of Economic Studies, 65(4), 655-669.

[9] Cho, I.-K., and D. M. Kreps (1987), Signalling Games and Stable Equilibria, Quarterly Journal of Economics, 102(2), 179-221.

[10] Dana, J., and K. Spier (2006), Bundling and Product Reputation, Northwestern University, mimeo.

[11] Erdem, T. (1998), An Empirical Analysis of Umbrella Branding, Journal of Marketing Research, 35(3), 339-351.

[12] Hakenes, H., and M. Peitz (2008), Umbrella Branding and the Provision of Quality, International Journal of Industrial Organization, 26(2), 546556.

[13] Sporleder, T. L. and P. D. Goldsmith (2001), Alternative Firm Strategies for Signalling Quality in the Food System, Canadian Journal of Agricultural Economics/Revue Canadienne d'Agroeconomie, 49(4), 591-604.

[14] Tadelis, S. (1999), What's in a Name? Reputation as a Tradeable Asset, American Economic Review, 89(3), 548-563.

[15] Mikós-Thal, J. (2007), On the Signalling and Feedback Effects of Umbrella Branding, University of Toulouse, mimeo. 
[16] Wernerfelt, B. (1988), Umbrella Branding as a Signal of New Product Quality: An Example of Signalling by Posting a Bond, RAND Journal of Economics, 19(3), 458-466.

[17] Wernerfelt, B. (1994), An Efficiency Criterion for Marketing Design, Journal of Marketing Research, 31(4), 462-470. 